\title{
Adiar o fim do mundo, que história é essa Krenak?
}

\author{
To postpone the end of the world, what are you talking about \\ krenak?
}

Cláudio Rodrigues da Silva ${ }^{1}$

Agnes Iara Domingos Moraes ${ }^{2}$

Amanda Cristina Danaga ${ }^{3}$

O livro "Ideias para adiar o fim do mundo" é uma "provocação" - que sintetiza um conjunto de provocações -, a começar pelo título, que envolve, simultaneamente, algum nível de casualidade e causalidade.

O autor do livro é Ailton Krenak, uma histórica liderança no movimento indígena brasileiro, conhecido nacional e internacionalmente, em especial pelos seus posicionamentos em defesa dos direitos dos povos indígenas, bem como por suas críticas às políticas desenvolvimentistas, que degradam a natureza, colocando em risco as condições de vida, humana e não humana, no Planeta. Krenak tem longo histórico de atuação em defesa da conquista e garantia do direito dos povos indigenas, o que inclui, necessária e indissociavelmente, a tríade terra-território-territorialidade, imprescindivel para a vida desses povos. Como reconhecimento da sua atuação, a Universidade Federal de Juiz de Fora outorgou-lhe, em 2016, o título de Doutor Honoris Causa.

KRENAK, Ailton. Ideias para adiar o fim do mundo. São Paulo: Companhia das Letras, 2019. $85 \mathrm{p}$.

${ }^{1}$ Doutorado em Educação pela Universidade Estadual Paulista, Faculdade de Filosofia e Ciências. Professor substituto no Instituto de Biociências, Letras e Ciências Exatas (Ibilce), da Universidade Estadual Paulista, campus de São José do Rio Preto/SP.

2 Doutorado em Educação pela Universidade Estadual Paulista, Faculdade de Filosofia e Ciências, campus de Marília/SP. Professora da Universidade Estadual de Mato Grosso do Sul (UEMS), Unidade Universitária de Paranaíba.

3 Pós-doutorado em Antropologia Social pela Universidade Federal de Santa Catarina/SC e Doutorado em Antropologia Social pelo Programa de Pós-Graduação em Antropologia Social da Universidade Federal de São Carlos/SP. Professora na Universidade Estadual de Mato Grosso do Sul (UEMS), Unidade Universitária de Paranaíba.

Interfaces da Educ., Paranaíba, v.11, n.32, p. 378 - 383, 2020

ISSN 2177-7691

Recebido em 21 de maio de 2020 e aceito em 21 de agosto de 2020 
Em formato de livro de bolso e totalizando 85 páginas, "Ideias para adiar o fim do mundo", lançado em 2019 pela Companhia das Letras, é composto por três textos, resultantes de entrevista e de versões adaptadas de duas palestras proferidas pelo autor em Portugal, entre 2017 e 2019. São, portanto, notas sobre diversas temáticas, em consonância com o objetivo original desses textos nas suas modalidades orais.

O primeiro texto é intitulado "Ideias para adiar o fim do mundo", o segundo, "Do sonho e da terra" e o terceiro, "A humanidade que pensamos ser". Nesses textos Krenak discute diversos temas prementes, que extrapolam a dimensão indígena e que estão sendo debatidos em nível internacional, pois envolvem, em última análise, as condições de continuidade da vida em âmbito planetário.

Krenak tece incisivas críticas às concepções hegemônicas de progresso, de desenvolvimento e de relação com a natureza, concepções essas pautadas pela lógica do mercado capitalista, o que implica tratar a natureza como mero recurso natural, como se a Terra fosse uma espécie de inesgotável estoque de matérias-primas, para levar adiante projetos desenvolvimentistas, insustentáveis ambientalmente, pois são incompativeis com a reprodução da vida humana no Planeta, o que remete à questão do Antropoceno. O autor aponta que a dessacralização e a despersonalização da natureza corroboram com a perspectiva hegemônica ocidental de transformar tudo em mercadoria. Em consonância com o pensamento ameríndio, Krenak propõe outra conceituação para aquilo que chamamos de natureza.

Krenak apresenta, também, críticas que envolvem o Estado-nação, os organismos internacionais, as instituições educacionais oficiais, a concepção hegemônica de ciência e de tecnologia, dialogando com clássicas discussões na área das Ciências Sociais sobre a não neutralidade dos conhecimentos científicos.

Outro tema abordado pelo autor é a pretensiosa (auto)proclamada universalidade da concepção ocidental de humanidade, que tenta impor seu modo de vida a todo o Planeta. 
A questão do rompimento, em 2015, da barragem no município de Mariana/MG também é abordada por Krenak, que reitera que esse rompimento não foi acidental, mas, sim, criminoso. Aliás, Krenak é o nome pelo qual é conhecido o povo que habita as margens esquerda do rio Doce, em Minas Gerais.

$\mathrm{O}$ autor apresenta alguns questionamentos que instigam a reflexões sobre os objetivos e as formas de intervenção humana no Planeta, quais sejam: "Mas é esse o mundo que deixaram para a gente?" "Qual é o mundo que vocês estão agora empacotando para deixar às gerações futuras?" "Que mundo e que serviço de delivery você está pedindo?”

Krenak, que não tem pretensões de enquadramento nas lógicas acadêmico-científicas, mas que se insere como um exemplo de descolonização da produção do conhecimento científico, apresenta nesse livro discussões que remetem a diversas temáticas debatidas internacionalmente na atualidade, em especial por defensores das teses do Antropoceno e/ou do decrescimento.

O livro tem o potencial de instigar o público leitor a refletir sobre essas questões a partir de outra perspectiva, qual seja, a de povos originários, que se contrapõem à lógica hegemônica ocidentalocêntrica, até porque esses povos, que resistem há mais de 500 anos à inconclusa tentativa de conquista, vivem, não sem contradições e condições cada vez mais adversas, em conformidade com as respectivas culturas, menos suscetíveis à lógica consumista, típica do capitalismo. Para além dos modos de vida que constroem, em contraposição à ordem hegemônica imposta por setores do capital, tais povos, em suas mitologias, cosmologias e filosofias, sinalizam que já vivenciaram experiências escatológicas, sendo alguns deles, portanto, especialistas em fim de mundo, conforme Danowski e Viveiros de Castro (2014).

O livro foi posto em circulação num momento oportuno, haja vista os desafios enfrentados pelos povos indígenas, tanto no Brasil - especialmente em decorrência das políticas implementadas nos últimos anos pelo governo federal - quanto em outros países, devido, entre outros fatores, à Interfaces da Educ., Paranaíba, v.11, n.32, p. 378 - 383, 2020 
implementação de projetos desenvolvimentistas de diferentes portes, que resultam em impactos negativos em termos culturais, políticos e econômicos para esses povos, inclusive ameaçando ou mesmo inviabilizando suas condições de vida.

Destaca-se, também, a relevância da decisão do autor e da Companhia das Letras $^{1}$ de publicar esse livro, pois, historicamente, no Brasil, povos indígenas não têm, com alguma exceção, oportunidade de expressar seus posicionamentos, em especial suas críticas ou demandas, nos espaços institucionais e na mídia hegemônica. Aliás, essas publicações configuramse como lutas desses povos.

A publicação desses textos de Krenak em suporte impresso potencializa o alcance e a repercussão das ideias para adiar o fim do mundo. Além de romper com uma histórica praxe no Brasil, qual seja, a de tratar os povos indígenas como tutelados e infantes, como se fossem incapazes de decidir e de falar por si, essa publicação contribui para a difusão de aspectos das cosmovisões e das epistemologias desses povos. Contribui, ainda, para promover e divulgar o ativismo indígena também no plano das ideias, para um público não indígena, uma iniciativa de alta relevância, especialmente na atual conjuntura, em que, no Brasil, direitos constitucionais - tais como, liberdade de expressão e demarcação de terras indígenas - estão sob intensos e crescentes ataques, levados a termo por governantes, autoridades estatais, corporações nacionais e transnacionais, latifundiários, entre outros.

Adiar o fim do mundo configura-se como um dos principais desafios diante do Antropoceno, fenômeno que nos dias atuais tem conquistado maior repercussão, haja vista a pandemia da Covid-19, que está implicando algumas alterações radicais - cujos efeitos demandam análises mais abrangentes e aprofundadas - na vida das populações de diversos países e continentes, resultando em diversos posicionamentos de variados grupos

1 Essa editora também publicou, em 2015, "A queda do céu: palavras de um xamã yanomami", de autoria de Davi Kopenawa e Bruce Albert, um livro que contribui para a compreensão de diversos aspectos do pensamento do povo Yanomami (KOPENAWA; ALBERT, 2015).

Interfaces da Educ., Paranaíba, v.11, n.32, p. 378 - 383, 2020 
sociais, posicionamentos esses que se configuram uma espécie de espectro, que inclui desde o fatalismo, conveniente à ordem social vigente, a questionamentos que colocam em tela a possibilidade e/ou a necessidade de transformações estruturais, especialmente em termos de posturas da humanidade na relação com o Planeta. Recorrendo a palavras de Krenak,

\begin{abstract}
Nosso tempo é especialista em criar ausências: do sentido de viver em sociedade, do próprio sentido da experiência da vida. Isso gera uma intolerância muito grande com relação a quem ainda é capaz de experimentar o prazer de estar vivo, de dançar, de cantar. E está cheio de pequenas constelações de gente espalhada pelo mundo que dança, canta, faz chover. O tipo de humanidade zumbi que estamos sendo convocados a integrar não tolera tanto prazer, tanta fruição de vida. Então, pregam o fim do mundo como uma possibilidade de fazer a gente desistir dos nossos próprios sonhos. E a minha provocação sobre adiar o fim do mundo é exatamente sempre poder contar mais uma história. Se pudermos fazer isso, estaremos adiando o fim. (KRENAK, 2019, p. 26-27)
\end{abstract}

Contar mais uma história. Como Xerazade, em As mil e uma noites (1961), contar, enquanto necessário for, mais uma história. Contar histórias rebeldes, histórias muy otras, configura-se como uma forma de se contrapor à ordem social vigente, que difunde e se alimenta de histórias de falta de alternativas, visando a naturalização do projeto que está em curso, como se a situação atual fosse inevitável, independesse da atuação humana, inexistindo, portanto, alternativas. Contar histórias, como Xerazade, como uma forma de resistência, de adiar o fim do mundo, contribuindo para a busca e a apresentação de alternativas ou mesmo substitutivas. Histórias que suscitem esperança em perspectivas críticas, em contraposição à esperança e ao otimismo ingênuos e conservadores, que induzem ao imobilismo e que reiteram o status quo.

Contar histórias, dançar, rezar, sonhar, são modos de resistência figurados por meio da ideia dos paraquedas coloridos, como tentativa de vislumbrar outras politicas e poéticas a fim de interromper o fascínio desmedido pelo consumo e pela mercadoria. Assim, em vista de muitos pedaços de mundo que já morreram e tantos pedaços de céu que já caíram, como indicam as narrativas ameríndias, para tardar o fim do mundo, ao menos da concepção de mundo que nós humanos temos, urge apreender Interfaces da Educ., Paranaíba, v.11, n.32, p. 378 - 383, 2020 
com aqueles que continuam pisando suavemente sobre a terra e dançando para suspender e segurar o céu. Nesse sentido, alerta Krenak, contar mais uma história, não como metáfora, mas como friç̧ão.

Um dos pontos altos do livro em tela é sustentar que há alternativas e apostar no potencial contraditório das ideias, como mais uma forma de contribuir para as mobilizações sociais, bem como apostar no protagonismo e na capacidade de agência humana para a busca de alternativas e de substitutivas, a exemplo do que apontam estudos em perspectivas contrahegemônicas sobre o Antropoceno e teorias do decrescimento, inclusive para, metafórica e literalmente, adiar o fim do mundo.

\section{Bibliografia}

AS MIL E UMA NOITES. Trad. Nair Lacerda; Domingos Carvalho. São Paulo: Saraiva, 1961.

DANOWSKI, Débora; VIVEIROS DE CASTRO, Eduardo. Há mundo por vir? Ensaio sobre os medos e os fins. Florianópolis: Cultura e Barbárie, 2014.

KOPENAWA, Davi; ALBERT, Bruce. A queda do céu: palavras de um xamã yanomami. São Paulo: Companhia das Letras, 2015. 